\title{
Population of indigenous yeast strains from Prieto Picudo grapes in different growing areas of Denomination of Origin «Tierra de León»
}

\author{
José Manuel ÁLVAREZ-PÉREZ*, Enrique GARZÓN-JIMENO, Juan José R. COQUE \\ Research Institute of Vineyard and Wine. University of León. Avda. Portugal, 41. 24071, León, Spain. \\ ${ }^{*}$ Corresponding author, e-mail: jmalvp@unileon.es
}

Bulletin UASVM Horticulture 72(1) / 2015

Print ISSN 1843-5254, Electronic ISSN 1843-5394

Doi:10.15835/buasvmcn-hort:11013

\begin{abstract}
Many different studies about autochthonous yeast populations and their potential use as starters in the fermentation process have been conducted. However it is not clear enough which is the most suitable environment to sampling with the purpose of isolating the best indigenous yeast populations. Most researches had carried out the isolation in fermentative environments (cellars), although other studies sampled in natural habitats (vineyards). Yeast isolation was made from Prieto Picudo grape samples taken from different vineyards which are spread in the cultivation area of this variety. Different yeast species have been identified unequivocally by molecular techniques. Major were yeast species associated to this natural habitats (named "indigenous yeast"), although a Saccharomyces cerevisiae strain was isolated too. Furthermore this Saccharomyces 3d strain was isolated in two different vineyards (with a separation area of approximately $50 \mathrm{~km}$ ). Accordingly, this strain could be considered as a "terroir strain". Small-scale fermentations were made with this strain. Their oenological properties were compared with the average properties of a collection of yeast strains isolated in our laboratory in fermentative habitats (cellars). Results show that the Saccharomyces 3d strain couldn't produce a complete fermentation, therefore is not suitable as a starter in an industrial process. Therefore, the isolation of autochthonous yeast strains must be done in fermentative habitats (cellars) in order to achieve success.
\end{abstract}

Keywords: autochthonous yeasts, indigenous yeasts, Prieto Picudo, Saccharomyces cerevisiae, wine.

\section{Introduction}

Prieto Picudo is a red grape variety quite grown almost exclusively in southern Leon (Castilla y León, north west Spain). The production area is located between two rivers (Cea and Esla), which influence climatic conditions of this region. Wines produced with this grape variety are included in the Denomination of Origen (DO) "Tierra de León" which currently comprises 40 cellars. Due to its youth (DO distinction was conferred in 2007) the grape production and number of bottles sold are in a constant increased, so an increment of 52 and 90 per cent, respectively, was achieved when compared 2000 and 2013 vintages (data provided by DO “Tierra de León"). Traditionally this variety is used in the elaboration of a singular semi-sparkling rosé wine, commonly named as "Rosado de aguja" because of the addition of grape brunches in the final stages of the fermentation process (this technique is locally known as "madreo"). Currently, the cellars also elaborate a great variety of red wines which are suitable for ageing. In fact, the first "Gran Reserva" wine (60 months ageing, 18 in oak) elaborated had a wide acceptance by consumers. The characterization of the aroma profile of Prieto Picudo rosé wines has recently been reported (Álvarez-Pérez et al., 2012). These wines are characterized by a complex aroma, pointing out the high levels of some thiols (i.e. 4-mercapto-4-methyl-2-pentanone) which are similar to those found in white wines from Sauvignon Blanc, where these compounds are 
considered varietal markers. Population analysis of yeasts in different cellars together with the influence in the final aroma and organoleptic properties of a wine by different autochthonous yeast strains was achieved in a recent study (Álvarez-Pérez et al., 2014). This study confirms the existence of a local and unique population in each cellar. Thereby, by an adequate selection process, each winery could produce wines with exclusive aromatic properties.

Several studies have linked the association of yeast population to a fermentation process and their influence in the final organoleptic properties of wines (for a complete review see Swiegers et al., 2005). There are approximately 100 genera of yeasts, however 15 of these are related to winemaking processes (Kurtman and Fell, 1998). According to their habitats, it is possible distinguish between yeasts associated to the grape surface (vineyards) and yeasts associated to the equipment surfaces of a winery (cellars) (Bisson and Lucy Joseph, 2009). Yeast population in grape surface is highly dependent on several factors like climatic conditions, cultivation methods, sanitary conditions, etc. Values from $10^{4}-10^{6}$ cells $/ \mathrm{cm}^{2}$ are estimated in grape surfaces (Fleet et al., 2002). Saccharomyces yeasts are in very low concentrations compared to the levels of other yeast genera. Thus, population is dependent on the maturation state of grape berries. Basidiomycete yeasts are predominant in early stages of maturation, giving way to ascomycete yeasts during the maturation process (Bisson and Lucy Joseph, 2009). In wineries, Saccharomyces cerevisiae is the predominant yeast in the installation surfaces, although it is possible to detect other yeasts like Candida, Cryptococcus or Brettanomyces, depending on the surface and its cleanliness (Pretorius, 2000). In a fermentation process, there are several selective pressures (nutrient depletion, anaerobic conditions, increasing level of ethanol) which favor yeast with the most efficient fermentative catabolism, like $S$. cerevisiae (Martini, 1993) and other closely related species such as S. bayanus (Pretorius et al., 1999).

In this study it is analyzed the population associated to different vineyards from different cellars, spread out of the production area of DO "Tierra de León". Yeasts were directly isolated from grapes of different locations and unequivocally identified by molecular techniques.
The results obtained were compared with the population of yeast isolated from fermentative habitats, specifically from the same cellars where the vineyards are located (Álvarez-Pérez et al., 2014). The comparison was made by different fermentation assays in order to assess the behavior in a semi-industrial process.

\section{MATERIALS AND METHODS}

\section{Grape samples}

Grape samples were kindly provided from vineyards by different cellars of DO "Tierra de León", from vineyards belonging to each one. We selected for this study the same cellars that in previous studies (Álvarez-Pérez et al., 2014): Gordonzello S.A. (Gordoncillo, León), Cooperativa de los Oteros (Pajares de los Oteros, León), Bodegas Pedro Casis (Gordaliza del Pino, León), Cooperativa Vinícola Ribera del Cea (Valderas, León), and Vinícola Valmadrigal (Castrotierra de Valmadrigal, León). The last one informed that they used grapes from Gordoncillo vineyards (the same grapes that Gordonzello S.A. winery), so there were not samples included from this cellar. Thus, four different samples were available for the analyses.

\section{Yeast isolation from grape samples}

Two different pre-weighted sterile bottles were filled out with the different grape samples and crushed in sterile conditions. One of these was supplemented with $5 \%(\mathrm{w} / \mathrm{w})$ of ethanol in order to enhance the isolation of Saccharomyces yeast. All samples were incubated at $10^{\circ} \mathrm{C}$. Every 15 days aliquots of $100 \mu \mathrm{L}$ from serially diluted samples in sterile water were plated on WL nutrient agar (Sharlau, Barcelona, Spain) plates supplemented with $150 \mu \mathrm{g} / \mathrm{mL}$ chloramphenicol (Sigma-Aldrich, St. Louis, MO, USA) to avoid bacterial growth. Plates were incubated at $10{ }^{\circ} \mathrm{C}$ until the occurrence of microbial colonies. Several colonies, with different morphology, were randomly selected and replicated in YPD-Agar plates (Lodder, 1970), that were incubated at $28{ }^{\circ} \mathrm{C}$ for $2-3$ days. Then they were stored at $4{ }^{\circ} \mathrm{C}$ until the analyses took place. Clones were named with a number indicating the sampling period (i.e. "O" stands for initial sampling, "1" first biweekly sampling and so on), followed by a consecutive letter for each sampling period (i.e. " $2 \mathrm{e}$ " indicating a clone " $\mathrm{e}$ " isolated at the second biweekly period, that is to say, 1 month from the start of incubation). 


\section{Characterization of yeast species}

Yeast identification was carried out by the D1D2 regions of 26S rDNA sequencing (O'Donnell 1993; Villa-Carvajal et al., 2004); and confirmed, when it was required, by RFLP (restriction fragment length polymorphism) analysis of the 5.8S-ITS-rDNA region (González et al., 2006). Yeast total DNA was isolated from $5 \mathrm{~mL}$ cultures grown in YPD (Lodder, 1970) at $28^{\circ} \mathrm{C}$ and 200 $\mathrm{rpm}$ for $24 \mathrm{~h}$. Cells were harvested and suspended in $400 \mathrm{~mL}$ of solution A (sorbitol, 1M; EDTA, $0.1 \mathrm{M}$; $\mathrm{pH}$ 7.5). Next they were treated by adding $50 \mathrm{~mL}$ of Zymolyase-20T (ICN Biomedicals Inc., Morgan Irvine, CA, USA) and incubated at $37^{\circ} \mathrm{C}$ for $1 \mathrm{~h}$. Protoplasts were recovered by centrifugation, resuspended in $400 \mathrm{~mL}$ of solution B (EDTA, 20 $\mathrm{mM}$; Tris-HCl, $50 \mathrm{mM}$; pH 7.4), and lysed by adding $10 \mathrm{~mL}$ of SDS $20 \%$ and incubation at $65^{\circ} \mathrm{C}$ for 10 min. Next $160 \mathrm{~mL}$ of $5 \mathrm{M}$ potassium acetate were added and the preparation was strongly agitated and incubated on ice for $10 \mathrm{~min}$. Cellular debris was pelleted by centrifugation at 13,000 rpm for 15 min. Supernatant was recovered and treated by adding $1 \mathrm{~mL}$ of RNase $(10 \mathrm{mg} / \mathrm{ml}$ ) (Fermentas, Glen Burnie, MD, USA) at $37^{\circ} \mathrm{C}$ for $20 \mathrm{~min}$. The sample was cleaned by phenol-chloroform extraction and the DNA present in the aqueous phase was precipitated by adding 1 volume of isopropanol. DNA was finally dissolved in $20 \mathrm{ml}$ of TE buffer and preserved at $-20^{\circ} \mathrm{C}$ until use. strains

Genetic typing of Saccharomyces cerevisiae

S. cerevisiae strain typing was carried out by RFLP of mitochondrial DNA analysis (RFLPmtDNA) by using different endonucleases (Querol et al., 1992). Bands profiles were bioinformatics analyzed by using InfoQuest FP software package (Bio-Rad, Hercules, CA, USA). It was possible the comparison between the different polymorphisms obtained resulting in dendrograms (UPGMA) according to the coefficient of similarity (DICE algorithm) as reported in (Álvarez-Pérez et al., 2014).

\section{Pure microfermentations}

Microfermentations were made by duplicate by using $500 \mathrm{~mL}$ bottles filled with $350 \mathrm{~mL}$ of sterile grape must. Prieto Picudo grape must was sterilized by filtration through $0.22 \mu \mathrm{m}$ filters (Millipore, Billerica, EEUU). Each microvinification was inoculated with one milliliter of a yeast preinoculum $($ OD600 $=1)$ from overnight cultures $\left(28{ }^{\circ} \mathrm{C} / 200 \mathrm{rpm}\right)$. Wine fermentations were carried out at $20^{\circ} \mathrm{C}$ and monitored by measuring the loss of weight every 24 hours until the end of the process (constant weight). After this, yeast cells were removed by centrifugation $(5 \mathrm{~min} /$ $4000 \mathrm{rpm})$. Samples were stored at $-20{ }^{\circ} \mathrm{C}$ until quantitative analyses were performed.

\section{Chemical quantitative analyses}

Wines obtained by pure microfermentations were quantitative analyzed. Levels of glucose, fructose, glycerol, ethanol and acetic acid in wines were measured by HPLC using an Agilent 1200 series (Agilent Technologies, Santa Clara CA, USA) chromatograph endowed with a refraction index detector (RID), and a variable wavelength detector (VWD). The instrument was equipped with a HyperREZ XP Carbohydrate $\mathrm{H}^{+}$column (8 $\mu \mathrm{m}$ particle size, $300 \times 7.7 \mathrm{~mm}$ ) and a HyperREZ XP carbohydrate $\mathrm{H}^{+}$Guard pre-column (Thermo Scientific, Waltham, USA), kept at $50{ }^{\circ} \mathrm{C}$. Analysis, from a 1:5 dilution of the wines and a 1:25 dilution of grape must were carried out after filtering the samples through $0.45 \mu \mathrm{m}$ cellulose acetate filters (Costar, Washington DC, USA). The detection of sugars (glucose, fructose), glycerol and ethanol, was achieved by using a RID detector (positive polarity) at a flow rate of $0.8 \mathrm{ml} / \mathrm{min}$ with $4 \mathrm{mM}$ $\mathrm{H}_{2} \mathrm{SO}_{4}$ as mobile phase (injection volume $25 \mu \mathrm{L}$ ). Quantifications of products were performed according to area peaks referring to calibration curves obtained with standard products.

\section{Mathematical data processing}

The fermentation process was controlled by measuring of the weight loss each 24 hours(as described above). Graphical representation of cumulative weight loss with regard to the time elapsed in each point leads a curve that reports the behavior of a particular yeast strain (see Fig. 1). However, normalization was required for comparative purposes. Sugar content (mainly glucose and fructose) of the initial must and residual sugars in different wines obtained was achieved by HPLC analyses. A new variable, $\mathrm{Z}$ (weight loss cumulative percentage) was defined. The curve obtained by representing this new variable ( $Z$, percentage) versus time elapsed (days) was fitted to a non-lineal model (re-parameterized Gompertz equation) (Gompertz, 1825) by using Statistica 7 software (StafSoft, Inc., IL, EEUU). This model is defined by three empirical parameters: Latency time (l), maximum fermentation rate 

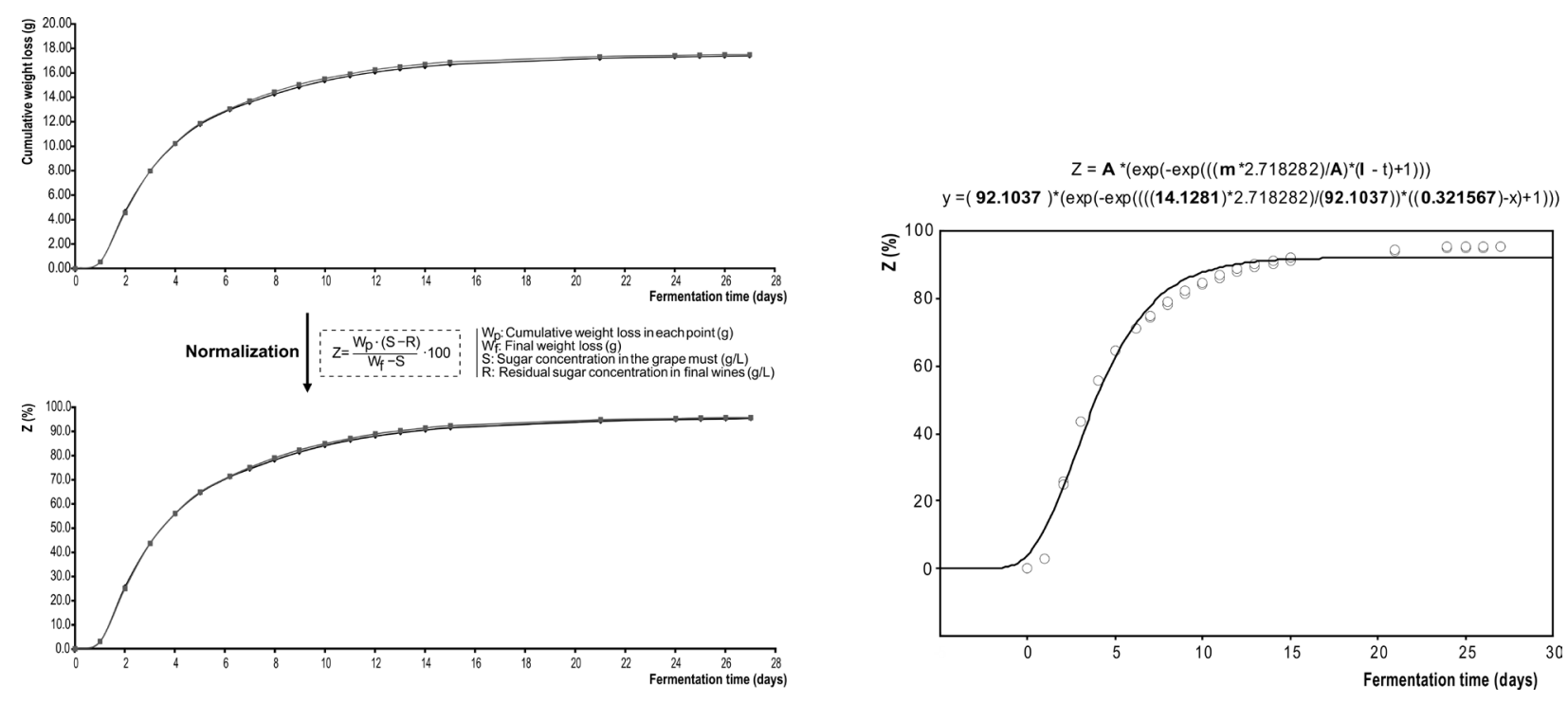

a

b

Fig.1. (a) Normalization process to the fermentation curves (Cumulative weight loss vs Fermentation time); (b) Each fermentation curve was adjusted to a non-lineal model. The behavior in a fermentation process is described by the empirical parameters obtained $(\mathrm{A}, \mathrm{m}, \mathrm{l})$.

(m) and percentage of sugars fermented (A). The behavior of each strain was related to the values of these parameters (see Fig. 1b).

\section{RESULTS AND DISCUSSION}

\section{Yeast strains genetic characterization}

In previous studies (Álvarez-Pérez et al., 2014) we analyzed the population of yeast associated to a fermentative environment. Thus, 900 yeasts were isolated and characterized from Prieto Picudo grape must samples provided by different wineries (see section 2.1). A collection of 119 Saccharomyces yeasts was obtained: 118 Saccharomyces cerevisiae and a $S$. cerevisiae x $S$. kudriavzevii hybrid yeast. In the present study we analyzed the population of yeasts associated to the natural environment, consisting of different vineyards of Prieto Picudo grapes spread out of the cultivation area of the DO "Tierra de León" . A total of 58 yeast strains, in 7 different samplings (initial sample and six different biweekly samplings), were selected and analyzed. Yeast identification was made by the D1-D2 regions of 26S rDNA sequencing. Table 1 summarizes the identification results.

In the initial samplings wild yeasts were identified and those which predominate at the surface of grapes. According to different authors the main genera of yeasts associated to grape surface were isolated and identified: Hanseniaspora uvarum and Metschnikowia pulcherrima (Beltran et al., 2002; Combina et al., 2005; Hierro et al., 2006; Bisson and Lucy Joseph, 2009). Also, different species of basidiomycete Cryptococcus were identified together with Rhodotorula and dimorphic fungi Aureobasidium as described by some authors (Prakitchaiwattana et al., 2004). Two different Cystofilobasidium, C. capitatum and C. lari-marini, were identified according NCBI blast. However, according to a taxonomic study (Sampaio et al., 2001) based on DNA-DNA reassociation experiments it has been reported that $C$. lari-marini must be regarded as a synonym of $C$. capitatum.

In a third sampling (6 weeks after starting the incubation) one of the yeast isolated, named $3 d$, was identified as Saccharomyces cerevisiae. In the fourth sampling three of the yeasts analyzed (named 4a, 4d and 4i) were again identified as $S$. cerevisiae. In the fifth sampling only the 5 b clone was identified as $S$. cerevisiae. In the final sixth sampling ( 12 weeks after starting theincubation) most of the yeasts analyzed were unequivocally identified as $S$. cerevisiae (see Tab. 1). Isolation of this yeast in natural environmental is possible, even at low levels (Martini et al., 1996; Prakitchaiwattana et al., 2004). Our data support this statement because they show that population of Saccharomyces yeast increase with incubation 
Tab. 1. Yeast isolated at low temperature $\left(10^{\circ} \mathrm{C}\right)$ from Prieto Picudo grape samples from different locations. The sampling period, vineyard where it was isolated and if the original sample was supplemented with ethanol are indicated. Furthermore, the fragment size amplified by using NL1 and NL4 primers it is also reported. Yeasts were identified according to NCBI nucleotide BLAST.

\begin{tabular}{|c|c|c|c|c|c|}
\hline Sample & Sampling & Vineyard/Winery & EtOH & Size (bp) & Identification by sequencing (BLAST) \\
\hline Oá & 0 & Gordonzello & $\mathrm{N}$ & 680 & Cryptococcus laurentii \\
\hline $\mathrm{Ob}$ & 0 & Gordonzello & $\mathrm{N}$ & 680 & Cryptococcus terrestris \\
\hline Oc & 0 & Gordonzello & $\mathrm{N}$ & 680 & Cystofilobasidium capitatum \\
\hline Od & 0 & Gordonzello & $\mathrm{N}$ & 680 & Cryptococcus amylolentus \\
\hline $\mathrm{Oe}$ & 0 & Gordonzello & $\mathrm{N}$ & 680 & Rhodotorula nothofagi \\
\hline Of & 0 & Gordonzello & $\mathrm{N}$ & 660 & Cryptococcus flavescens \\
\hline Og & 0 & Gordonzello & $\mathrm{N}$ & 660 & Cryptococcus flavescens \\
\hline $\mathrm{Oh}$ & 0 & Gordonzello & $\mathrm{N}$ & 660 & Aureobasidium pullulans \\
\hline $\mathrm{Oi}$ & 0 & Gordonzello & $\mathrm{N}$ & 650 & Cryptococcus flavescens \\
\hline $0 \mathrm{j}$ & 0 & Pedro Casis & $\mathrm{N}$ & 650 & Cryptococcus victoriae \\
\hline Ok & 0 & Coop. Los Oteros & $\mathrm{N}$ & 680 & Cryptococcus sp. \\
\hline Ol & 0 & Coop. Vin. Ribera Cea & $\mathrm{N}$ & 680 & Cryptococcus victoriae \\
\hline Om & 0 & Coop. Vin. Ribera Cea & $\mathrm{N}$ & 650 & Aureobasidium pullulans \\
\hline On & 0 & Pedro Casis & $\mathrm{N}$ & 600 & Metschnikowia pulcherrima \\
\hline Oo & 0 & Pedro Casis & $\mathrm{N}$ & 600 & Metschnikowia pulcherrima \\
\hline $1 \mathrm{a}$ & 1 & Pedro Casis & $\mathrm{N}$ & 650 & Cryptococcus victoriae \\
\hline $1 \mathrm{~b}$ & 1 & Pedro Casis & $\mathrm{N}$ & 600 & Metschnikowia pulcherrima \\
\hline 1c & 1 & Coop. Vin. Ribera Cea & $\mathrm{N}$ & 630 & Aureobasidium pullulans \\
\hline $1 \mathrm{e}$ & 1 & Coop. Vin. Ribera Cea & $\mathrm{N}$ & 650 & Filobasidium capsuligenum \\
\hline $1 \mathrm{~h}$ & 1 & Pedro Casis & $\mathrm{N}$ & 630 & Cryptococcus victoriae \\
\hline $2 a$ & 2 & Pedro Casis & $\mathrm{N}$ & 600 & Hanseniaspora uvarum \\
\hline $2 \mathrm{~b}$ & 2 & Pedro Casis & $\mathrm{N}$ & 550 & Cryptococcus amylolentus \\
\hline $2 \mathrm{c}$ & 2 & Gordonzello & $\mathrm{N}$ & 650 & Cryptococcus amylolentus \\
\hline $2 \mathrm{~d}$ & 2 & Gordonzello & $\mathrm{N}$ & 650 & Cystofilobasidium lari-marini \\
\hline $3 a$ & 3 & Pedro Casis & $\mathrm{N}$ & 550 & Metschnikowia fructicola \\
\hline $3 \mathrm{c}$ & 3 & Pedro Casis & $\mathrm{N}$ & 630 & Hanseniaspora uvarum \\
\hline $3 d$ & 3 & Pedro Casis & $\mathrm{N}$ & 650 & Saccharomyces cerevisiae \\
\hline $3 e$ & 3 & Pedro Casis & Y & 550 & Metschnikowia fructicola \\
\hline $3 f$ & 3 & Pedro Casis & Y & 550 & Metschnikowia sp. \\
\hline $3 g$ & 3 & Pedro Casis & Y & 550 & Metschnikowia fructicola \\
\hline $3 \mathrm{~h}$ & 3 & Coop. Vin. Ribera Cea & $\mathrm{N}$ & 650 & Leucosporidium scottii \\
\hline $3 \mathrm{i}$ & 3 & Gordonzello & $\mathrm{N}$ & 650 & Filobasidium capsuligenum \\
\hline $3 j$ & 3 & Gordonzello & $\mathrm{N}$ & 650 & Cystofilobasidium capitatum \\
\hline $4 a$ & 4 & Pedro Casis & $\mathrm{N}$ & 650 & Saccharomyces cerevisiae \\
\hline $4 \mathrm{~b}$ & 4 & Pedro Casis & $\mathrm{N}$ & 650 & Hanseniaspora uvarum \\
\hline $4 \mathrm{c}$ & 4 & Pedro Casis & $\mathrm{N}$ & 600 & Metschnikowia pulcherrima \\
\hline $4 d$ & 4 & Pedro Casis & $\mathrm{N}$ & 650 & Saccharomyces cerevisiae \\
\hline $4 \mathrm{e}$ & 4 & Gordonzello & $\mathrm{N}$ & 650 & Cystofilobasidium capitatum \\
\hline $4 \mathrm{f}$ & 4 & Pedro Casis & Y & 600 & Metschnikowia pulcherrima \\
\hline $4 \mathrm{~g}$ & 4 & Pedro Casis & Y & 600 & Metschnikowia pulcherrima \\
\hline $4 \mathrm{~h}$ & 4 & Coop. Vin. Ribera Cea & $\mathrm{N}$ & 650 & Hanseniaspora uvarum \\
\hline $4 \mathrm{i}$ & 4 & Coop. Vin. Ribera Cea & $\mathrm{N}$ & 650 & Saccharomyces cerevisiae \\
\hline $4 j$ & 4 & Coop. Vin. Ribera Cea & $\mathrm{N}$ & 600 & Metschnikowia pulcherrima \\
\hline $5 a$ & 5 & Coop. Vin. Ribera Cea & $\mathrm{N}$ & 650 & Hanseniaspora uvarum \\
\hline $5 b$ & 5 & Coop. Vin. Ribera Cea & $\mathrm{N}$ & 650 & Saccharomyces cerevisiae \\
\hline $5 c$ & 5 & Pedro Casis & Y & 550 & Metschnikowia fructicola \\
\hline $5 \mathrm{~d}$ & 5 & Pedro Casis & $\mathrm{Y}$ & 650 & Metschnikowia aff. fructicola \\
\hline $6 a$ & 6 & Coop. Vin. Ribera Cea & $\mathrm{N}$ & 650 & Saccharomyces cerevisiae \\
\hline $6 \mathrm{~b}$ & 6 & Coop. Vin. Ribera Cea & $\mathrm{N}$ & 650 & Saccharomyces cerevisiae \\
\hline $6 c$ & 6 & Coop. Vin. Ribera Cea & $\mathrm{N}$ & 650 & Saccharomyces cerevisiae \\
\hline $6 \mathrm{~d}$ & 6 & Pedro Casis & $\mathrm{N}$ & 650 & Saccharomyces cerevisiae \\
\hline $6 e$ & 6 & Pedro Casis & $\mathrm{N}$ & 650 & Saccharomyces cerevisiae \\
\hline $6 f$ & 6 & Pedro Casis & $\mathrm{N}$ & 650 & Saccharomyces cerevisiae \\
\hline $6 \mathrm{~g}$ & 6 & Pedro Casis & $\mathrm{N}$ & 650 & Saccharomyces cerevisiae \\
\hline $6 \bar{h}$ & 6 & Pedro Casis & $\mathrm{N}$ & 650 & Saccharomyces cerevisiae \\
\hline $6 i$ & 6 & Pedro Casis & $\mathrm{N}$ & 650 & Saccharomyces cerevisiae \\
\hline $6 j$ & 6 & Pedro Casis & Y & 550 & Metschnikowia aff. fructicola \\
\hline $6 \mathrm{k}$ & 6 & Pedro Casis & $\mathrm{Y}$ & 650 & Saccharomyces cerevisiae \\
\hline
\end{tabular}

$\mathrm{N}$ : No ethanol in grape sample; Y: $5 \%(\mathrm{w} / \mathrm{w})$ ethanol in grape sample 
time, displacing autochthonous yeasts of grape surface.

In order to perform the strain characterization of Saccharomyces strains, RFLP-mtDNA analyses were carried out. These analyses indicated that all $S$. cerevisiae strains were the same since their fingerprints were identical (Fig. 2). This data was very striking, since the different $S$. cerevisiae clones had been isolated from different vineyards in a wide geographical region. Thus this strain, named $3 d$ (as the first clon isolated), was isolated from samples of two different locations separated more than 50 kilometresfrom Pedro Casis winery vineyards (Gordaliza del Pino, León) and vineyards of Cooperativa Vinícola Ribera del Cea winery vineyards (Valderas, León). A comparison between this strain and the collection of 119 Saccharomyces strains isolated from fermentative environments

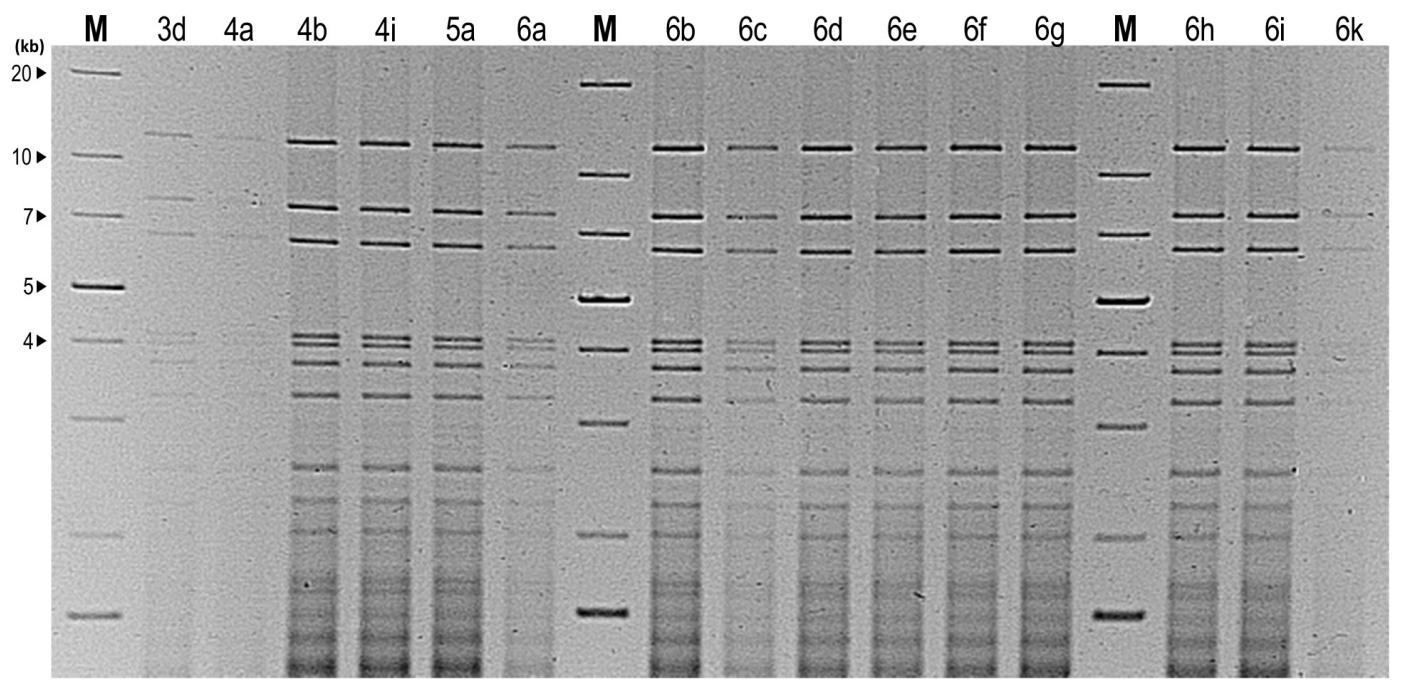

Fig. 2. RFLP-mtADN analyses of Saccharomyces cerevisiae yeasts isolated. M is the molecular weight ladder of $1 \mathrm{~kb}$ (Fermentas, Maryland, USA).
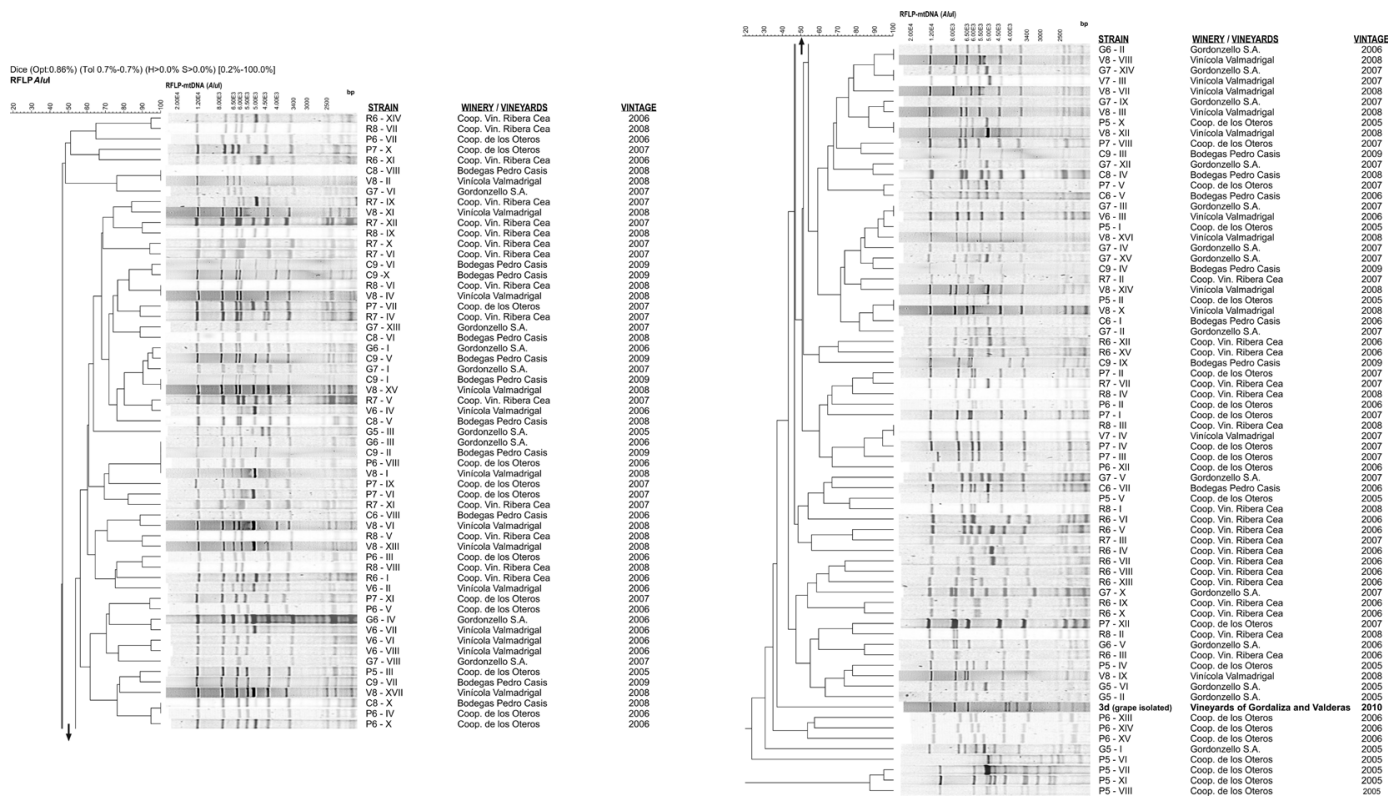

Fig.3. Comparison among the collection of yeast isolated from Prieto Picudo cellars (industrial environment) and the yeast isolated from grapes ( $3 \mathrm{~d}$ strain). Dendrogram (left) based on RFLP-mtDNA analyses with the restriction endonuclease AluI (centre) of all strains (right) is shown. The grape yeast isolated is highlighted in bold. 
(Álvarez-Pérez et al., 2014) was made. A bioinformatics analysis (as described above) leads us to ensure that $3 d$ strain was different from any other of the industrial collection (Fig. 3). Thereby we discarded a possible contamination of samples in our laboratory.

The fact that an unique strain of Saccharomyces cerevisiae had been isolated from different grape samples belonging to different cultivation areas (vineyards associated to different wineries) suggests the existence of a strain that can be considered as representative of an enological region or "terroir". Similar results were obtained by other authors in other regions (Vezinhet et al., 1992; Versavaud et al., 1995). The population of fermentative Saccharomyces strains in vineyards is very low (Martini et al., 1996; Prakitchaiwattana et al., 2004), in fact a Saccharomyces strain is rarely isolated from intact berries (Martini, 1993). In wine cellar acts differently since Saccharomyces cerevisiae is prevalent on these surfaces (Martini et al., 1996). This demonstrates the selective effect of grape juice and wine as growth substrates (Martini, 1993). In fact, some authors severed that cells of $S$. cerevisiae are rarely isolated from natural surfaces (including grapes) while natural fermentations of musts is carried out by winery resident flora (Martini et al., 1996). Yeast strains are non-motile, so they rely on aerosols, animal vectors, mainly insects, and human activity for their natural dispersal (Mortimer and Polsinelli, 1999). Therefore is unclear the origin of $3 d$ strain in different vineyards. Insects may have an important role in the spread of this strain in the cultivation region.

Saccharomyces cerevisiae has been one of the most important model microorganism in research, butaboveallthisspecieis one of the microorganisms most appreciated microorganisms by humans because of its utility in the production of several foods and drinks (Stefanini et al., 2012). Today, we have broad knowledge about its genetic and phenotypic traits, however its origin and evolution process are still unclear. Some authors predict a natural origin (Martini, 1993) of wine yeast strains while others attribute its origin to fermentative environments, man-made niches, like wineries (Fay and Benavides, 2005). The first genetic diversity characterization of $S$. cerevisiae isolated from several sources showed clear differences between wild (natural origin) and domesticated (fermentative origin) strains (Fay and Benavides, 2005). A most recent study (Liti et al., 2009) over the complete genome of $36 \mathrm{~S}$. cerevisiae unveils five "clean" lineages, where one of them comprises a number of wine strains as well as European nonwine strains (called wine/European population). The other lineages corresponded to lineages from other sources and different origins. Maybe, a natural origin of Saccharomyces strains will be assumed, although a domestication process, due to fermentation processes, may explain the differential properties among strains according to their habitat.

\section{Oenological characterization of the Saccharomyces strain}

As indicated in the previous section we analyzed the yeast population in grapes from different cultivation areas under DO "Tierra de León". Only one strain of Saccharomyces cerevisiae was isolated between populations of wild yeasts normally associated to this natural environment. This strain was used in the elaboration of experimental wines (pure microvinifications, see above) that were analyzed by HPLC. In a previous study (Álvarez-Pérez et al., 2014) the population of yeast associated to fermentative habitat was also analyzed in this way. A comparison of the performance of the isolated grape yeast ( $3 d$ strain) against fermentative yeasts provided experimental information about different biochemical features of this microorganism in relation to its habitat. The values of the $3 d$ strain, for each parameter, are indicated by a cross in a box-plot graph (Fig. 4) that informs about collection of yeasts previously analyzed (Álvarez-Pérez et al., 2014).

Wines elaborated with the $3 d$ strain (grape isolated) had high levels of residual sugars (10.20 $\mathrm{g} / \mathrm{L})$ when compared with those elaborated with yeast isolated from fermentative environment. Most of yeasts produced wines with low sugar levels (Fig. 4a). This is in accordance with the ethanol content in the final wine, since $13.06 \%$ vol. is slightly lower to ethanol content in relation to other Prieto Picudo laboratory wines in the same way elaborated. This value is lower than minimum in the blox-plot graph (Fig. 4b). Glycerol content $(6.11 \mathrm{~g} / \mathrm{L})$ can be considered as normal according to several authors (Ough et al., 1972; Scanes et al., 1998). In fact, the $3 d$ value almost coincides with the median in the corresponding box-plot graph (Fig. 4c). In relation to experimental fermentation 

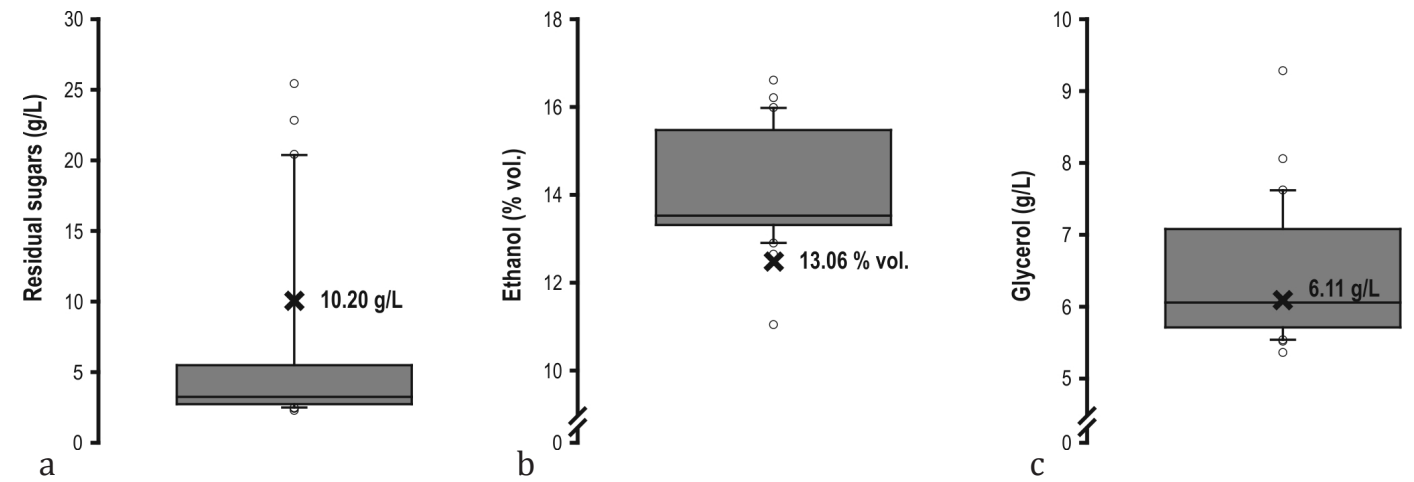

Fig.4. Box-plot graphs of different oenological parameters of fermentative collection yeast (Álvarez-Pérez et al., 2014). Shown with a cross the values obtained with the " $3 d$ " yeast strain. (a) Residual sugar content (g/L). (b) Ethanol content (\% vol.). (c) Glycerol content (g/L).

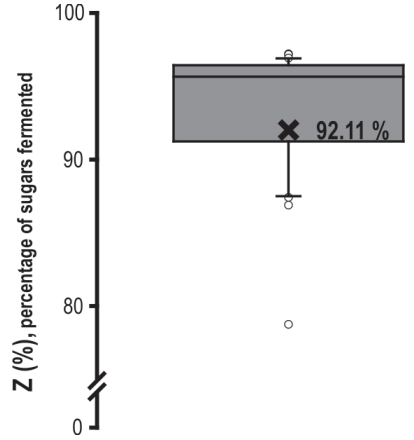

a

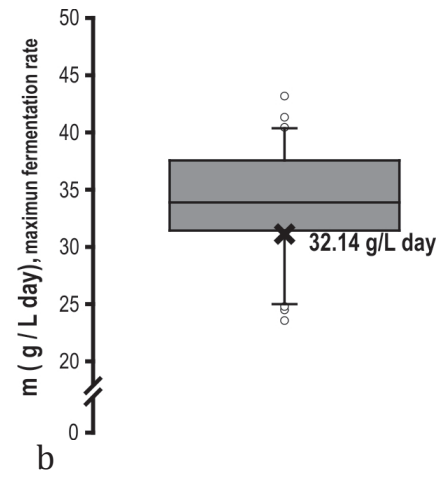

Fig.5. Box-plot graphs of empirical parameters of fermentation behavior of fermentative yeast collection (Álvarez-Pérez et al., 2014). Shown with a cross the values obtained with the " $3 d$ " yeast strain. (a) Percentage of sugars fermented (Z, $\%$ ). (b) Maximum fermentation rate ( $\mathrm{m}, \mathrm{g} / \mathrm{L}$ day).

parameters evidenced again great difference between the isolated grape strain and the collection of fermentative yeasts. The percentage fermented (A) by $3 d$ strain was slightly higher to Q1 in the corresponding box-plot graph (Figure 5a), that it is to say that only the $25 \%$ of fermentative strains showed a weaker performance in these conditions. The same conclusion can be applied to the fermentation rate parameter (m), whose value is close to Q1 in the graph (Figure $5 \mathrm{~b}$ ).

During biomass production and the alcoholic fermentation the yeast cells are subjected to several stresses, highlighting the osmotic stress mainly due to high sugar concentration and the increasing level of ethanol (Querol et al., 2003). A particular characteristic of industrial yeast is the presence of polymoaphic chromosomes (Codón et al., 1998) due to several spontaneous mutations like the recombination between transposable Ty elements (Rachidi et al., 1999), mitotic crossing over and gene conversions and others (Querol et al., 2003). These mechanisms are a response to very selective pressures (mentioned above) in order to achieve faster adaptation to environmental changes (Puig and Pérez-Ortín, 2000). This adaptation is commonly called as "domestication". By these reasons the physiological behavior of a yeast strain isolated from natural environmental diverge from those whose principal niche is an industrial environment (Liti et al., 2009). Our experimental results are in accordance with previous observations. The strain isolated from vineyard showed a weaker performance in relation to fermentation yeasts from different wineries of DO "Tierra de León" (Álvarez-Pérez et al., 2014). For this reason, the isolation of yeast strains with the aim of being used in industrial fermentations is not suitable. Selection of autochthonous yeast strains of a particular winery is the right methodology to ensure success as has been demonstrated in a previous study (ÁlvarezPérez et al., 2014). In fact, a commercial wine 
was elaborated using autochthonous yeast. This wine has exclusive aromatic properties clearly distinguishable from other commercial wines, both of this or other wineries.

\section{CONCLUSIONS}

The results of this research are relevant in two ways. One of them it is the population studies of Saccharomyces strains over different habitats. This study revealed that Saccharomyces strains are in low proportion over wild yeast in natural habitat. Furthermore, the oenological studies showed that wild Saccharomyces do not have efficient catabolic system associated to fermentation processes in relation to autochthonous strains of cellars. It was noticeable that the same $S$. cerevisiae strain (named 3d) was isolated in different vineyard dispersed over cultivation area. This strain may be considered like "terroir" of this cultivation area.

The final aim of yeastisolation and/or selection is aimed at its possible industrial application. One strategy used is the isolation of yeast in natural habitats like vineyards. In fact, some companies offer this service to the wineries. The results shown that the "wild" S. cerevisiae strain was unable to produce a complete fermentation (high levels of residual sugar in the final wine) therefore could not be used as a good starter in a wine elaboration process. Only $S$. cerevisiae strains isolated from fermentative habitats (domestication process) may be used for this purpose if their oenological properties are suitable. So, companies or institutions that offer this service to wineries incur in an economic and scientific fraud. This research studies may be useful highlight the importance of a correct isolation and selection of yeast strains with potential industrial properties.

\section{REFERENCES}

1. Álvarez-Pérez JM, Álvarez-Rodríguez ML, Campo E, Sáenz de Miera LE, Ferreira V, Hernández-Orte P, Garzón-Jimeno E, Coque JJR (2014). Selection of Saccharomyces cerevisiae strains applied to the production of Prieto Picudo rosé wines with a different aromatic profile. S Afr J Enol Vitic 35:242-256.

2. Álvarez-Pérez JM, Campo E, San-Juan F, Coque JJR, Ferreira V, Hernández-Orte P (2012). Sensory and chemical characterisation of the aroma of Prieto Picudo rosé wines: The differential role of autochthonous yeast strains on aroma profiles. Food Chem 133: 284-292.

3. Beltran G, Torija MJ, Novo M, Ferrer N, Poblet M, Guillamón JM, Rozès N, Mas A (2002). Analysis of yeast populations during alcoholic fermentation: a six year follow-up study. Syst Appl Microbiol 25:287-293.

4. Bisson LF, Lucy Joseph CM (2009). Yeasts, p. 47-60. In: König H, Unden G, Fröhlich J (Eds.) Biology of Microorganisms on Grapes, in Must and in Wine. Springer Berlin Heidelberg, Berlin.

5. Codón AC, Benítez T, Korhola M (1998). Chromosomal polymorphism and adaptation to specific industrial environments of Saccharomyces strains. Appl Microbiol Biot 49:154-163.

6. Combina M, Mercado L, Borgo P, Elia A, Jofré V, Ganga A, Martinez C, Catania C (2005). Yeasts associated to Malbec grape berries from Mendoza, Argentina. J Appl Microbiol 98:1055-1061.

7. Fay JC, Benavides JA (2005). Evidence for domesticated and wild populations of Saccharomyces cerevisiae. PLoS Genet 1:66-71.

8. Fleet GH, Prakitchaiwattana G, Beh A, Heard G (2002). The Yeast ecology of wine grapes, p. 1-17. In: Ciani M (Ed.) Biodiversity and biotechnology of wine yeasts. Research Signpost. Kerala, India.

9. Gompertz B (1825). On the nature of the function expressive of the law of human mortality, and on a new mode of determining the value of life contingencies. Philos T R Soc Lond 115:513-583.

10. González SS, Barrio E, Gafner J, Querol A (2006). Natural hybrids from Saccharomyces cerevisiae, Saccharomyces bayanus and Saccharomyces kudriavzevii in wine fermentations. FEMS Yeast Res 6:1221-34.

11. Hierro N, González A, Mas A, Guillamón JM (2006). Diversity and evolution of non-Saccharomyces yeast populations during wine fermentation: effect of grape ripeness and cold maceration. FEMS Yeast Res 6:102-111.

12. Kurtman C, Fell J (1998). The Yeast, A Taxonomic Study, fourth edition. Elsevier Science, Amsterdam, The Netherlands.

13. Liti G, Carter DM, Moses AM, Warringer J, Parts L, James SA, Davey RP, Roberts IN, Burt A, Koufopanou V, Tsai IJ, Bergman CM, Bensasson D, O’Kelly MJT, van Oudenaarden A, Barton DBH, Bailes E, Nguyen AN, Jones M, Quail MA, Goodhead I, Sims S, Smith F, Blomberg A, Durbin R, Louis EJ (2009). Population genomics of domestic and wild yeasts. Nature 458:337-41.

14. Lodder J (1970). The yeasts, a taxonomic study. North Holland Publising Company, Amsterdam, The Netherlands.

15. Martini A (1993). Origin and domestication of the wine yeast Saccharomyces cerevisiae. Journal of Wine Research 4:165-176.

16. Martini A, Ciani M, Scorzetti G (1996). Direct enumeration and isolation of wine yeasts from grape surfaces. Am J Enol Vitic 47:435-440.

17. Mortimer R, Polsinelli M (1999). On the origins of wine yeast. Res Microbiol 150:199-204.

18. O'Donnell K (1993). Fusarium and its near relatives, p. 225-233. In: Reynolds DR, Taylor JW (Eds.) The fungal holomorph: mitotic, meiotic and pleomorphic speciation in fungal systematics. CAB International, Wallingfork, UK. 
19. Ough CS, Fong D, Amerine MA (1972.) Glycerol in wine: determination and some factors affecting. Am J Enol Vitic 23:1-5.

20. Prakitchaiwattana CJ, Fleet GH, Heard GM (2004) Application and evaluation of denaturing gradient gel electrophoresis to analyse the yeast ecology of wine grapes. FEMS Yeast Res 4:865-877.

21. Pretorius IS (2000) Tailoring wine yeast for the new millennium: novel approaches to the ancient art of winemaking. Yeast 16:675-729.

22. Pretorius IS, van der Westhuizen TJ, Augustyn OPH (1999) Yeast biodiversity in vineyards and wineries and its importance to the South African Wine Industry - A Review. S Afr J Enol Vitic 20:61-74.

23. Puig S, Pérez-Ortín JE (2000). Stress response and expression patterns in wine fermentations of yeast genes induced at the diauxic shift. Yeast 16:139-148.

24. Querol A, Barrio E, Ramón D (1992). A comparative study of different methods of yeast strain characterization. Syst Appl Microbiol 15:439-446.

25. Querol A, Fernandez-Espinar M, del Olmo M, Barrio E (2003). Adaptive evolution of wine yeast. Int J Food Microbiol 86:3-10.

26. Rachidi N, Barre P, Blondin B (1999). Multiple Ty-mediated chromosomal translocations lead to karyotype changes in a wine strain of Saccharomyces cerevisiae. Mol Gen Genet 261:841-850
27. Sampaio JP, Gadanho M, Bauer R (2001). Taxonomic studies on the genus Cystofilobasidium: description of Cystofilobasidium ferigula sp. nov. and clarification of the status of Cystofilobasidium lari-marini. Int J Syst Evol Microbiol 51:221-229.

28. Scanes K, Hohmann S, Prior B (1998). Glycerol production by yeast Saccharomyces cerevisiae and its relevance to wine: a review. S Afr J Enol Vitic 19:17-24.

29. Stefanini I, Dapporto L, Legras J-L, Calabretta A, Paola MD, Filippo CD, Viola R, Capretti P, Polsinelli M, Turillazzi S, Cavalieri D (2012). Role of social wasps in Saccharomyces cerevisiae ecology and evolution. PNAS 109(33): 1339813403.

30. Swiegers J, Bartowsky E, Henschke P, Pretorius I (2005). Yeast and bacterial modulation of wine aroma and flavour. Aust J Grape Wine R 11:139-173.

31. Versavaud A, Courcoux P, Roulland C, Dulau L, Hallet JN (1995). Genetic diversity and geographical distribution of wild Saccharomyces cerevisiae strains from the wineproducing area of Charentes, France. Appl Environ Microbiol 61:3521-3529.

32. Vezinhet F, Hallet J-N, Valade M, Poulard A (1992). Ecological survey of wine yeast strains by molecular methods of identification. Am J Enol Vitic 43:83-86.

33. Villa-Carvajal M, Coque JJR, Álvarez-Rodríguez LM, Uruburu F, Belloch C (2004). Polyphasic identification of yeasts isolated from bark of cork oak during the manufacturing process of cork stoppers. FEMS Yeast Research 4:745-750. 